\title{
Report
}

\section{Some Features of the Dental Metal Implant Changes with Different Character of a Surface After Administration into Bone Tissue of Rabbits}

\author{
Michael S. Toder ${ }^{1}$, Andrew I. Shevela ${ }^{2}$, Alexander A. Shevela ${ }^{1,3}$, Paul A. Zheleznyi ${ }^{3}$, \\ Anna P. Zheleznaia ${ }^{3}$, Igor V. Mayborodin' \\ ${ }^{1}$ Department of Implantology of International Center of Implantology the Ident-Clinic, Novosibirsk, Russia \\ ${ }^{2}$ Center of new Medical Technologies of Institute of Chemical Biology and Fundamental Medicine of the Siberian Branch of the Russian \\ Academy of Science, Novosibirsk, Russia \\ ${ }^{3}$ Department of Pediatric Dentistry of Novosibirsk State Medical University, Novosibirsk, Russia
}

Email address:

imai@mail.ru (Igor V. Mayborodin)

\section{To cite this article:}

Michael S. Toder, Andrew I. Shevela, Alexander A. Shevela, Paul A. Zheleznyi, Anna P. Zheleznaia, Igor V. Mayborodin. Some Features of the Dental Metal Implant Changes with Different Character of a Surface After Administration into Bone Tissue of Rabbits. International Journal of Dental Medicine. Vol. 2, No. 1, 2016, pp. 1-4. doi: 10.11648/j.ijdm.20160201.11

Received: March 10, 2016; Accepted: May 17, 2016; Published: June 16, 2016

\begin{abstract}
Screw metal implants with rough or the smooth polished were introduced surface in a tibial bone proximal condyle of not purebred rabbits. Within 6 months after operation the considerable distinctions of radiological data were revealed not. 2 months later after introduction of implants with a rough surface the effort enclosed for its twisting is, much more, than for removal of the polished product. However, stability of fixing of implants was practically made even at 6 months. On remote rough implants there is a set of tissue scraps whereas on products with a smooth surface the tissue remains were much less. Surrounding tissues strongly join a rough surface, grow into cavities, and during removal of such products there is a considerable trauma of tissues round an implantation place. Smooth implants have the smaller area of contact with organism tissues, they are fixed due to bicortical implantation, during removal easily get out and don't break off surrounding tissues.
\end{abstract}

Keywords: Screw Metal Dentistry Implants, Intra Bone Implantation, Durability of Implant Fixing, Features of Implant Removal

\section{Introduction}

Dental implantation is a method of implantation of an artificial tooth root (implant) in the top or lower jaw. Implants use as support on which fix or the crowns (which are fully replacing the lost teeth), or removable dentures (in this case implants promote adequate fixing of an artificial tooth in an oral cavity). The design of an implant consists of two main parts - the implant which represents the titanic screw implanted in a jaw in the surgical way and an abatment (external part of an implant - in a form reminds the ground tooth) which joins to implant after the healing period.

The requirement of biochemical compatibility and implants fixation and body tissues can be resolved satisfactory, if one applies the materials with rough surface, which is able to fix firmly to the living tissue. Two linking methods between implant and living tissue are created there: a mechanical adhesion due to the formation (growing in) of the tissue into the implant pores and chemical adhesion due to the interrelation of the tissue with implant content elements. The sort of material and nature of surface has an influence on reactions going on at living tissue-implant partition line $[1,2]$.

Tissue response to the intrusion of a foreign body usually includes inflammation, vascular responses and its separation by connective tissue [3-8]. Minimal expression of inflammatory process (low number of leukocytes in the tissue, weak expression of vascular response), absence of giant cells 
of foreign bodies in metal implants enclosing tissues, insufficient thickness of connective tissue capsule for all terms of research indicates the inertness of such materials for living organism, high compatibility of many metals with biological tissues $[1,2]$.

The tests of new articles, their comparison with the applicable articles, testing the new methods of implantation is carried out on experimental animals. The best suitable for this goal are rabbits, specifically proximal condyle of their shin bone, the structure of which corresponds to some human bones very closely. Besides, this part of the extremity of these animals are easy accessible. Due to it, very many researchers use this model for experimental implantation.

The objective of the study was defined based on the mentioned above: To define changes of a surface of metal screw dental implants with a rough or smooth surface after introduction in a bone.

\section{Materials and Methods}

Metal articles with various type of surface: rough dental implant with grit blasting and acid processing (3S, Israel) and smooth polished article for bicortical dental implantation $(3 \mathrm{~S}$, Israel) were implanted into proximal condyle of shin bone of 10 non-pedigreed rabbits.

All manipulations with the animals were not connected with distress and carried out in compliance with «Regulations on the works using experimental animals». The implantation was carried out with all aseptic and antiseptic rules in terms of sterile operating room under general anesthesia based on total intravenous anesthesia by propofol. At the initial stage marginal vein of auricle was punctured and catheterized by 24 $\mathrm{G}$ catheter, which were fixed by adhesive plaster. The intravenous premedication was carried out: atropine sulphate $0,1 \%$ - 0,22-0,27 mg/kg; benadryl $1 \%$ - 4,6-5,2 mg/kg; droperidol $0,25 \%$ - 1,25 mg; ketorolac trimetamine $1 \%-10$ $\mathrm{mg}$. Propofol $1 \%-15 \mathrm{mg} / \mathrm{kg}$ was used intravenously as anesthesia induction, propofol $1 \%$ - 25-30 $\mathrm{mg} / \mathrm{kg} /$ hour intravenopusly was also used for support of anesthesia. The infusion therapy was effected by $0,9 \%$ sodium chloride solution of $15-25 \mathrm{ml} / \mathrm{kg}$, depending on the expression of blood loss. The respiratory support when necessary was carried out by mask method with $100 \%$ oxygen insuflation.

Removal of hair was carried out by surgical scissors on the place of supposed surgical invasion on both extremities at knee joints. After manipulations the skin was processed by alcohol, the operation field was covered with a sterile nap with a hole.

For implantation of articles with rough surface the left extremity was chosen, for implantation of smooth implants the right extremity was chosen. It is necessary to note that the introduction of each implant into the same extremity of different animals firstly gives an opportunity to accelerate the implantation procedure itself, because there is no need to register what animal and what extremity an article was implanted into; secondly, it makes further observation and examination of animals easier.
The sequence of manipulations for implantation:

1. The skin section was made by disposable scalpel along the front line a little bit below the knee joint.

2. The tissues were moved apart to the periosteum by the blunt method (closed branches of the forceps).

3. The surface of proximal condyle of shin bone was exposed by the rasp at the front-medial side.

4. The hole in chosen part was made by the dentist's drill up to the "downfall". 2 bores of increasing diameter are used.

5. The implant was screwed into the made hole by hand and then by the spanner with dynamometric scale, allowing to control the force created. The implant head goes beyond the bone surface for not more than $1 \mathrm{~mm}$.

6. Operative wound was taken in by vicryl 5-0 on each layer.

7. Skin stitches were treated by $5 \%$ alcohol-iodine solution.

The animals get rid of stitches by themselves within 1-2 weeks after the operation, there were no visual signs of acute inflammatory process. In most cases for all times the implants were placed on introduction place: in proximal condyle of tibial bone.

All rats were x-rayed every week to control the location of foreign bodies and early determination of potential complications. There is one case of osteomyelitis development after the implantation in the group as a whole and one case of rough and polished implants (different animals). The break of the extremity at the implantation place was detected during the last examination, the complication was found 1 week after the operation and it probably occurred at the time of or immediately after the implantation. Such animals were rejected and did not participate in further studies.

For studying of an implant surfaces the animals were taken out of the experiment 2 or 6 months after the operation by overdose of inhalation ether narcosis. Due to the fact that it was necessary to evaluate the conditions of surrounding tissues and to determine suppurative complications around before removal of foreign bodies, it is reasonable to preliminary remove the entire skin from the extremity from inguinal fold to down to the ankle. In cases, when the implant head was covered by tissues, it was released by the scalpel. Then the spanner with dynamometric scale was put onto it and the implant was screwed out step by step, registering the force at the beginning of its turn. After removal of foreign body a hole with even edges remained in tissues with traces of thread pane.

For further research the implants together with tissues on their surface were fixed in 4\% para-formaldehyde solution on phosphate buffer not less than 24 hours, then were investigated in the conditions of a combination of the transmitted and reflected light by the microscope Axioimager M1 (Zeiss, Germany) at magnification to 1200 times.

Statistical data processing was carried out by means of application statistic program MS Excel 7.0 (Microsoft, USA), arithmetic mean and error of arithmetic mean (standard deviation) were determined. The reliability of differences of 
compared mean values was determined on the basis of Student's test. As reliable was considered the difference between compared rows with confidence level of $95 \%$ and more. The calculations considered that the distribution of researched features was near to normal.

\section{Results and Discussion}

From radiological point of view the implants were placed at introduction places for all the times: in proximal condyle of shin bone. It is necessary to note that at the places where implant heads were (contact with periosteum) in 4 weeks after the operation some radiological signs of its irritation (thickening) appear. After 2 weeks these signs became more expressed (fig. 1a, b). After 6 months the response of periosteum to the foreign body did not change, after removal of implants radiological parts of decreased density remain after the removal of implants. The increase of density is noted in external areas of condyle, where the implant was introduced - its head; and at the opposite side - where the implant end rests (fig. 1c, d).

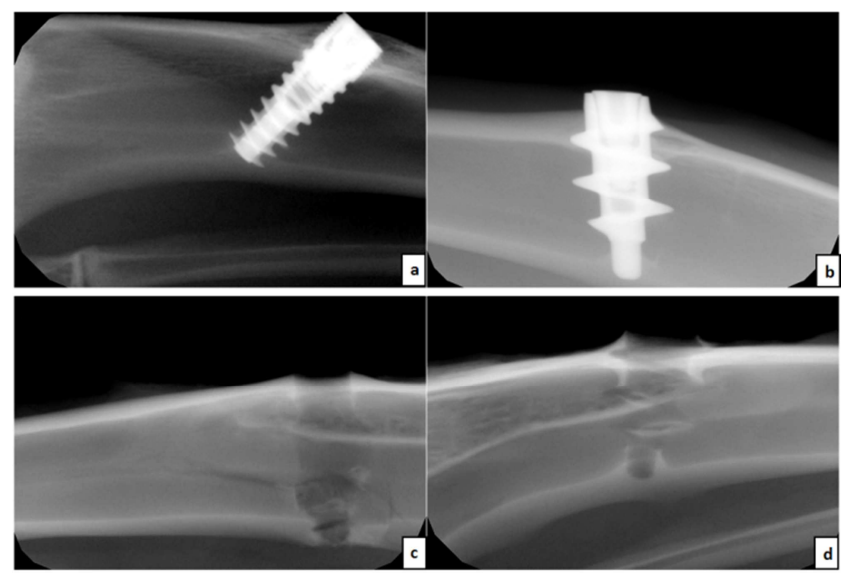

Fig. 1. The radiological results of introduction of metal screw implants with various character of a surface into rabbits' tibial proximal condyle. a - In 2 months after introduction the implant with a rough surface is located in a condyle of a tibial bone, there is a periosteum thickening in the field of a product head. $b$ - 2 months later after surgical intervention the polished implant is present in a condyle of a tibial bone where there is a periosteum thickening. $c$-After removal of rough implant 6 months later in a bone tissue there are sites of the reduced density according to an arrangement of a screw thread sides, the increase of bone density is noted only in external areas of a condyle where the product is established. $d$-After removal of smooth implants in 6 months after operation in a bone there are depression sites corresponding to an arrangement of sides of a product, the increase in density of bone is noted only in periostum areas where the head and the end of an implant are located.

2 months after the implantation a double difference was found between the compared articles during processing of statistic data on the force applied to the unscrewing implants: $46 \pm 8,94 \mathrm{Ncm}$ has the rough implant, and $23 \pm 18,2 \mathrm{Ncm}$ has the polished implant. 6 months after the operation the force of the unscrewing implants was equal to $67,5 \pm 9,57 \mathrm{Ncm}$ (rough implant) and 52 $\pm 5,42 \mathrm{Ncm}$ (smooth implant) respectively. All differences were however unreliable due to a big value of error of arithmetic means.
Multiple fragments of tissues were found macro- and microscopically at the removed implants with gritblasted surface and further itching (fig. 2a, b). There were much less fragments of tissues on articles with smooth surface (fig. 2c, d).

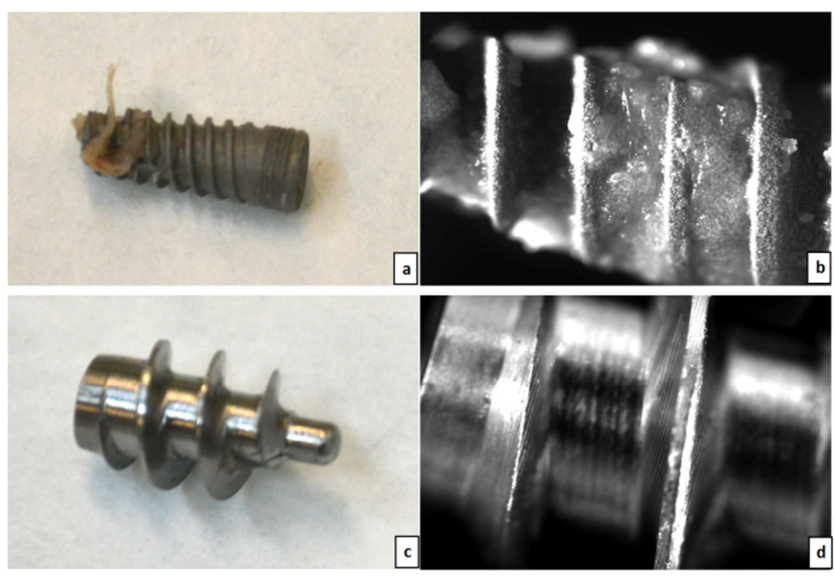

Fig. 2. The appearance of metal screw implants with various character of a surface after removal from organism tissues. $a$ - On a rough surface of a remote implant in 2 months after operation there are tissue fragments. $b-$ Tissue fragments on various structures of a remote product with a rough surface 6 months later after surgical intervention. $c$ - The polished surface of a remote implant 2 months later after operation is brilliant and almost pure. $d$ - Tissue fragments on the smooth implant in 6 months after operation are practically absent.

The surrounding tissues are firmly connected to the rough surface of the implants, they grow into pores, and when such articles are unscrewed, the significant traumatization of tissues surrounding the place of implantation. Smooth polished implants have less contact area with the tissues of organism, they are fixed due to bicortical implantation, they are easy unscrewed by removal and do not break the surrounding tissues. Because of that there were many fragments of tissues on removed implants with gritblasted surface, and there were almost no fragments of tissues on articles with smooth surface.

At the place of contact of living tissues with the implant, the tissues respond to the foreign body [3-5]. There are many reports in literature about atrophic and even necrotic changes in tissues contacting with foreign bodies [2, 9-11]. Probably, the implants immediately after their introduction into the bone firstly initiate acute inflammatory reaction due to surgical trauma and direct interaction of living tissues with the firm non-elastic non-living substance. Acute inflammatory process is gradually changed by chronic one and as it goes out slowly the full union of implant surface with the bone occurs.

In 2 months after implantation the implant with a rough surface was fixed in tissues much more strongly. It is possible to assume that the smaller effort enclosed during removal of the polished implant is compensated by stronger fixing by bicortical implantation. After 6 months, however, durability of implants fixation increased in both cases, but this index for the article with smooth surface increased more significantly. To this time the mean values in the group as a whole became almost equal. Probably, the implant with rough surface is fixed in tissues quicker due to its growing into the pores of articles 
itself. By introduction of the polished material, this process goes a bit slower, but it takes some time however. For rabbits it takes 6 months and leads as a result to the firm fixation of implanted metal.

During removal of the article the dense and very strong connections of tissue with a rough metal surface are broken off and, respectively, on this objects there is a set of soft tissue fragments and, probably, it is impossible to exclude presence of bone fragments. That is the damage rate of tissues during removal of an implant with a rough surface is much higher, and necessary time for a reparation of the remained defect - is more, than when twisting a product from the polished metal.

\section{Conclusion}

Thus, within 6 months after operation the considerable distinctions of radiological data were revealed not. 2 months later after introduction of implants with a rough surface the effort enclosed for its twisting is, much more, than for removal of the polished product. However, stability of fixing of implants was practically made even at 6 months. On remote rough implants there is a set of tissue scraps whereas on products with a smooth surface the tissue remains were much less. Surrounding tissues strongly join a rough surface, grow into cavities, and during removal of such products there is a considerable trauma of tissues round an implantation place. Smooth implants have the smaller area of contact with organism tissues, they are fixed due to bicortical implantation, during removal easily get out and don't break off surrounding tissues.

\section{References}

[1] Günter W. E., Dambayev G. Ts., Sysolyatin P. G., etc. Medical materials and implants with shape memory. Tomsk: Publishing house Tomsk un-that, 1998. $487 \mathrm{p}$.
[2] Mă̈borodin I. V., Iakushenko V. K., Maĭborodina V. I. Interaction of nickelide-titanium implant with tissues in human. Arkh Patol. 2002, vol. 64, № 2, p. 50-52.

[3] Marborodin I. V., Shevela A. I., Matveeva V. A. et al. Morphological tissue changes after the implantation of elastic lamellar foreign bodies in the experiment. Morfologiia. 2012, vol. 141, № 2, p. 54-60.

[4] Maiborodin I. V., Kuznetsova I. V., Beregovoy E. A. et al. Tissue reactions during the degradation of polylactide implants in the body. Morfologiia. 2013, vol. 143, № 3, p. 59-65.

[5] Maĭborodin I. V., Shevela A. I., Kuznetsova I. V. et al. Tissue responses to silicone materials in the body. Arkh Patol. 2013, vol. 75 , № 4 , p. $28-33$.

[6] Miro-Mur F., Hindié M., Kandhaya-Pillai R. et al. Medical-grade silicone induces release of proinflammatory cytokines in peripheral blood mononuclear cells without activating T cells. J. Biomed. Mater. Res. B Appl. Biomater., 2009, vol. 90, № 2, p. 510-520.

[7] Rodriguez A. and Anderson J. M. Evaluation of clinical biomaterial surface effects on $\mathrm{T}$ lymphocyte activation. J. Biomed. Mater. Res. A., 2010, vol. 92, № 1, p. 214-220.

[8] Rodriguez A., Meyerson H. and Anderson J.M. Quantitative in vivo cytokine analysis at synthetic biomaterial implant sites. J. Biomed. Mater. Res. A., 2009, vol. 89, № 1, p. 152-159.

[9] Gabriel S. E., Woods J. E., O'Fallon W.M. et al. Complications leading to surgery after breast implantation. N. Engl. J. Med., 1997, vol. 336, № 10, p. 677-682.

[10] Kanhai R. C., Hage J. J., Karim R. B., Mulder J.W. Exceptional presenting conditions and outcome of augmentation mammaplasty in male-to-female transsexuals. Ann. Plast. Surg., 1999, vol. 43, № 5, p. 476-483.

[11] Tebbetts J. B. A system for breast implant selection based on patient tissue characteristics and implant-soft tissue dynamics. Plast. Reconstr. Surg., 2002, vol. 109, № 4, p. 1396-1409. 